\title{
The Effect of "Multiphase Sedation" in the Course of Computed Tomography and Magnetic Resonance Imaging on Children, Parents and Anesthesiologists
}

\author{
Guray Demir ${ }^{1}$, Zafer Cukurova ${ }^{2}$, Gulay Eren 2, Yasemin Tekdos 2, Oya Hergunsel ${ }^{2}$
}

Summary: Demir G, Cukurova Z, Eren G, Tekdos Y, Hergunsel O - The Effect of "Multiphase Sedation" in the Course of Computed Tomography and Magnetic Resonance Imaging on Children, Parents and Anesthesiologists.

Background and objectives: We aimed to investigate the effect on children undergoing Computed Tomography (CT) or Magnetic Resonance Imaging (MRI), their parents and attending anesthesiologist of "multiphase sedation" which we define as "the intended sedation level achieved with one or more agents through the same or different routes with more than one administration".

Material and Methods: One hundred children and their parents were randomly allocated to one of two study groups. In phase 1; in Group I the patients were given midazolam $\left(0.5 \mathrm{mg} \cdot \mathrm{kg}^{-1}\right)$ in $5 \mathrm{~mL}$ fruit juice, and the ones in control group (Group II) were given only fruit juice. After intravenous (iv) cannulation; in phase II, boluses of propofol were given to achieve the adequate sedation for imaging. Anxiety scores of children and their parents were recorded using Oucher scale and STAI, respectively, and parental satisfaction was evaluated by visual analogue scale (VAS). The number of attempts for iv cannulation, length of time for preparation, and amount of hypnotics were recorded.

Results: Anxiety state of children was similar between groups before premedication, but later it was lower in Group I. Before procedure, STAI score of parents was similar and later it was lower in Group I. Parental satisfaction in Group I was higher. The number of attempts for iv cannulation and required propofol dose was less in Group I.

Conclusion: "Multiphase sedation" procedure provides children to feel less pain and anxiety, and decreases parental anxiety while increasing their satisfaction. It supplies a comfortable and safe sedation, as it provides a short and problem-free preparation process for the attending anesthetist as well.

Keywords: Anxiety; Child; Deep Sedation; Magnetic Resonance Imaging; Tomography.

\section{INTRODUCTION}

Children frequently require sedation in order to be cooperative and immobile for imaging modalities in radiology units, namely the magnetic resonance imaging (MRI) and computerized tomography (CT) procedures ${ }^{1-6}$. Moreover, imaging procedures that are not applied under adequate sedation necessitates repetition of the procedure, resulting in a significant loss of revenue to the institution, lost work time and, perhaps most importantly, delayed diagnosis.

A variety of sedative agents, including chloral hydrate, benzodiazepines, pentobarbital, methohexital, ketamine, thiopental and propofol have been effectively used through either oral,

Received from Tatvan State Hospital, Bitlis, Turkey.

1. Tatvan State Hospital, Bitlis, Turkey

2. Bakirkoy Dr.Sadi Konuk Research and Training Hospital, Istanbul, Turkey

Submitted on September 11, 2011.

Approved on December 20, 2011.

Correspondence to:

Guray Demir, MD

Cumhuriyet M. Hurriyet C. 23E 71 ,

Esenyurt

34515 - Istanbul, Turkey

E-mail: guraydemir@hotmail.com rectal or parenteral routes to facilitate imaging procedures in children 6-12. However, no data exist on whether a specific anesthetic technique is superior. Agent administered and the route of administration brings about a variety of advantages and disadvantages. It is well known that rectally administered chloral hydrate causes prolonged sedative effect due to its active metabolites; intramuscular or intravenous (iv) ketamine endangers airway safety increasing the secretions; and benzodiazepines alone may fail to provide adequate sedation ${ }^{6-9}$.

Intravenously administered propofol and agents alike have advantages of rapid onset, effective and adjustable anesthesia with rapid recovery ${ }^{13}$. Therefore, iv techniques are preferable.

Sedation is required not only for facilitation of immobility necessary to complete MRI and CT in children but also to reduce both child's and parental anxiety. As was revealed by the study of Kain et al. ${ }^{14}$ parental anxiety is directly correlated with children's anxiety and their coping with invasive medical procedures.

In this study, we aim to define "multiphase sedation" and study its effects on child, parents and the attending anesthesiologist. We define "multiphase sedation" as the intended sedation achieved with one or more agents through the same or different routes with more than one administration. In accordance with the definition, in the first phase of sedation, oral midazolam was given, then an iv line (a pain inducing pro- 
cedure) was inserted under mild-moderate level of sedation, and then child was separated from parents. Thus, it is aimed to cause less pain and agitation in a child, and decrease parental anxiety while increasing their satisfaction. In the second phase, intravenous propofol was administered in order to provide sufficient depth of sedation for completion of the imaging acquisition.

\section{MATERIALS AND METHODS}

With the approval of hospital ethics committee and informed consent of the parents, 100 children (ASA Physical status I-II) between 2-12 years of age, scheduled to undergo MRI or CT procedures with sedation as outpatients, and their parents were allocated to the study. Exclusion criteria were contraindication to sedation because of severe respiratory or metabolic deterioration, restricted oral intake or refusal of the patient for oral agent given for sedation, or failure of peripheral iv access. The parents with lower intellectual state who are supposed to fail to take the test for State and Trait Anxiety Inventory (STAI) ${ }^{15}$ were also excluded. The children and their parents were randomly assigned to one of two treatment groups. The subjects and the anesthesiologist were both blinded to the agents given. In the first phase of sedation, the children in the study group ( $n=50$, Group I, "multiphase sedation" group) were given 0.5 mg. $\mathrm{kg}^{-1}$ midazolam (F. Hoffman-La Roche Ltd. Basel, Switzerland), in 3-5 $\mathrm{mL}$ of clear fruit juice and the ones in control group ( $n=50$, Group II) were given the same amount of fruit juice only. Waiting 30 minutes after the application of first phase of sedation, children were taken together with parents to the preparation room where their iv access with 24 Gauge cannula was achieved. Later they were taken apart from their parents to the imaging room. ECG, $\mathrm{spO}_{2}$ and tension arterial were monitored. According to the child's clinical properties and length of imaging process, in the second phase, $1 \%$ propofol (Fresenius Kabi, Deutscland $\mathrm{GmbH}$ D-61346, Bad Homburg v.d.H, Germany) was administered $2 \mathrm{mg} \cdot \mathrm{kg}^{-1} \cdot \mathrm{min}^{-1}$ and titrated to provide the adequate depth of sedation, and their amount was recorded.

Children were allowed to breathe spontaneously and were just assisted with free flow of oxygen via facemask. Children were evaluated by Oucher scale, the Hispanic version ((http:// www.oucher.org/index.html) for pain and anxiety before first phase of sedation, during and after iv line insertion, and after separation from parents. We evaluated the parental anxiety before and after the imaging process using the State-Trait Anxiety Inventory ${ }^{15}$ which is a standard tool used by psychologists to assess situational anxiety. It consists of two 20question scores to which respondents are asked to indicate to what degree the item describes their feelings on a four-point Likert-type scale (where 1 = "not at all" and 4 = "very much so"). The first part (STAI I) measures the current emotional state of the subject, including immediate feelings of apprehension, nervousness and worry. The second set of questions (STAI II) measures the subject's personality trait or how the person generally feels. Because pediatric anesthesia is a dis- crete event, parents in the present study completed the state anxiety items as a measure of parental anxiety about their child's anesthesia.

Parents also revealed their level of satisfaction using a $100 \mathrm{~mm}$ visual analog scale (VAS) after the procedure. Other recorded parameters were the number of interventions for iv access and total time of stay at preparation room in the first phase; and in the second phase, required amount of propofol for adequate sedation were all recorded and evaluated.

\section{Statistics}

Statistical analysis was performed by SPSS (Statistical Package for Social Sciences) for Windows 15.0 software. In addition to descriptive statistical methods (mean \pm standard deviation), one-way Anova test was used to compare parameters with normal distribution, in the comparisons of more than two groups. Kruskal Wallis test was used to compare the parameters without normal distribution between more than two groups, and Mann Whitney $U$ test was performed to determine the group that caused the difference. In the comparisons between two groups Student $t$ test was used to compare parameters with normal distribution and Mann Whitney $U$ test for the parameters without normal distribution. Comparisons of qualitative data were performed with Chi-Square test. Statistical significance was assumed for $p \leq 0.05$.

\section{RESULTS}

Demographic parameters were similar between groups $(p>0.05)$. Mean age of parents included in the study was $30.03 \pm 5.70$ years and female/male ratio was $65 / 35$; mean age of children was $4.21 \pm 2.90$ years with a ratio of female/ male of $42 / 58$. The anxiety scores of the children regarding the Oucher scale were similar in groups in the first phase of sedation (9.49 \pm 25.17 vs $3.92 \pm 7.16$ in Group I and II respectively) ( $p=0.555, p>0.05)$. However, Oucher scores of children in Group I at the evaluation periods, during and after iv access, and on separation of children from parents, all were significantly lower than those in Group II (40.92 \pm 27.15 with a median of $40,8.57 \pm 13.84$ median 0 , and $23.88 \pm 29.71$ with a median 10 vs $80.00 \pm 25.69$ with a median of $90,25.29 \pm 28.16$ with a median of $20,58.14 \pm 35.34$ with a median of 70 , respectively) ( $p=0.001, p=0.001, p=0.001$ ) (Table I).

STAI II scores indicating the personality trait of the parents, which may affect the immediate feelings and emotional state of them, didn't show any difference between groups $(p=0.460)$. Likewise, results regarding the anxiety state of parents through STAI I scores, in the first phase, didn't reveal any significance $(46.97 \pm 10.06$ vs $43.92 \pm 8.22 ; p=0.099$, $p>0.05)$. But in the second phase, it was $41.36 \pm 8.23$ in Group I and $48.07 \pm 9.10$ in Group II, which was statistically significant $(p=0.001, p<0.05)$. Parents of the children in Group I were less anxious. Moreover, parental satisfaction evaluated by VAS was, as well, higher in Group I by $80.92 \pm 19.57$ vs 
$72.84 \pm 18.27(p=0.035, p<0.05)$. Therefore, it is seen that application of multiphase sedation increased parents' satisfaction while decreasing anxiety (Table II).

Concerning the administrator, the results were all on behalf of Group I. Number of attempts of iv access and the time of stay in the preparation room were lower in Group I. So, multiphase sedation provided a short and comfortable preparation process for the attending anesthesiologist as well. Moreover, children in Group I needed less amount of propofol in phase II to achieve the deep sedation needed for the imaging process

Table I - Comparison of Groups in Respect to Child Anxiety

\begin{tabular}{|c|c|c|c|}
\hline & $\begin{array}{l}\text { Group I } \\
(\mathrm{n}: 50)\end{array}$ & $\begin{array}{l}\text { Group II } \\
(\mathrm{n}: 50)\end{array}$ & $p$ \\
\hline $\begin{array}{l}\text { Oucher score before 1st } \\
\text { phase }\end{array}$ & $\begin{array}{l}9.49 \pm 25.17 \\
\text { (median } 0)\end{array}$ & $\begin{array}{l}3.92 \pm 7.16 \\
\text { (median 0) }\end{array}$ & $0.555^{\star}$ \\
\hline $\begin{array}{l}\text { Oucher score at time of } \\
\text { iv line insertion }\end{array}$ & $\begin{array}{l}40.92 \pm 27.15 \\
\text { (median 40) }\end{array}$ & $\begin{array}{l}80.00 \pm 25.69 \\
\text { (median 90) }\end{array}$ & $0.001^{\star ㅇ}$ \\
\hline $\begin{array}{l}\text { Oucher score after iv } \\
\text { line insertion }\end{array}$ & $\begin{array}{l}8.57 \pm 13.84 \\
\text { (median 0) }\end{array}$ & $\begin{array}{l}25.29 \pm 28.16 \\
\text { (median 20) }\end{array}$ & $0.001^{* o}$ \\
\hline $\begin{array}{l}\text { Oucher score on } \\
\text { separation from parents }\end{array}$ & $\begin{array}{l}23.88 \pm 29.71 \\
(\text { median } 10)\end{array}$ & $\begin{array}{l}58.14 \pm 35.34 \\
\text { (median } 70)\end{array}$ & $0.001^{* 0}$ \\
\hline
\end{tabular}

Group I: "multiphase sedation" group, Group II: control group; $p^{*}$ Mann Whitney $U$ test; $\mathrm{p}^{\mathrm{o}}$ statistically significant $(\mathrm{p}<0.05)$.

Table II - Comparison of Groups in Respect to Parental Anxiety and Parental Satisfaction

\begin{tabular}{llll}
\hline & $\begin{array}{l}\text { Group I } \\
(\mathrm{n}: 50)\end{array}$ & $\begin{array}{l}\text { Group II } \\
(\mathrm{n}: 50)\end{array}$ & $\mathrm{p}$ \\
\hline Trait anxiety (STAI II) & $47.51 \pm 9.64$ & $46.25 \pm 7.03$ & $0.460 \dagger$ \\
$\begin{array}{l}\text { State anxiety (STAI I) } \\
\text { before the procedure }\end{array}$ & $46.97 \pm 10.06$ & $43.92 \pm 8.22$ & $0.099 \dagger$ \\
$\begin{array}{l}\text { State anxiety (STAI I) } \\
\text { after the procedure }\end{array}$ & $41.36 \pm 8.23$ & $48.07 \pm 9.10$ & $\mathbf{0 . 0 0 1 \dagger ^ { \circ }}$ \\
$\begin{array}{l}\text { Parental satisfaction } \\
\text { after procedure (100mm }\end{array}$ & $80.92 \pm 19.57$ & $72.84 \pm 18.27$ & $\mathbf{0 . 0 3 5 \dagger ^ { \circ }}$ \\
\begin{tabular}{l} 
VAS) \\
\hline
\end{tabular}
\end{tabular}

Group I: "multiphase sedation" group, Group II: control group; p† Student t test $p^{\circ}$ statistically significant $(p<0.05)$. STAI: State and Trait Anxiety Inventory.

Table III - The Data of Anesthetic Procedures

\begin{tabular}{|c|c|c|c|}
\hline & $\begin{array}{l}\text { Group I } \\
(\mathrm{n}: 50)\end{array}$ & $\begin{array}{l}\text { Group II } \\
\text { (n:50) }\end{array}$ & $\mathrm{p}$ \\
\hline $\begin{array}{l}\text { Number of attempts for iv } \\
\text { line insertion (mean) }\end{array}$ & $1.14 \pm 0.50$ & $1.94 \pm 1.32$ & $0.001^{* 0}$ \\
\hline $\begin{array}{l}\text { Time of stay at preparation } \\
\text { room (min) }\end{array}$ & $4.72 \pm 1.68$ & $8.30 \pm 2.76$ & $0.001 \ddagger^{\circ}$ \\
\hline $\begin{array}{l}\text { Amount of propofol used in } \\
2^{\text {nd }} \text { phase }\left(\mathrm{mg} \cdot \mathrm{kg}^{-1}\right)\end{array}$ & $1.36 \pm 1.11$ & $2.47 \pm 0.67$ & $0.001 \ddagger^{\circ}$ \\
\hline Recovery time (min) & $21.06 \pm 6.58$ & $26.35 \pm 8.07$ & $0.001^{\star 0}$ \\
\hline
\end{tabular}

Group I: "multiphase sedation" group, Group II: control group; p* Mann Whitney $\mathrm{U}$ test; $\mathrm{p} \neq$ Chi-square test; $\mathrm{p}$ - statistically significant $(\mathrm{p}<0.05)$. $\left(1.36 \pm 1.11 \mathrm{mg} \cdot \mathrm{kg}^{-1}\right.$ propofol in Group I vs $2.47 \pm 0.67 \mathrm{mg} \cdot \mathrm{kg}^{-1}$ propofol in Group II; $p=0.001)$. Thus, recovery time was statistically lower in Group I (21.06 $\pm 6.58 \mathrm{~min}$ in Group I and $26.35 \pm 8.07 \mathrm{~min}$ in Group II, $p=0.001$ ) (Table III).

\section{DISCUSSION}

Apprehension and anxiety are normal in children undergoing medical procedures. Identifying and alleviating this anxiety is beneficial for many reasons besides enhancement of psychological well-being ${ }^{16,17}$. In recent years, anesthesiologists have increased their efforts to probe the emotional experiences of their patient's parents in addition to the patients themselves as they are in strict correlation.

Variables such as the age and temperament of the child and the state and trait anxiety of the parent have been identified as predictors for the occurrence of negative postoperative behavioral changes ${ }^{17}$. A significant proportion of parents experience anxiety and distress before their child's surgery or medical intervention. Previously it has been shown that there is a very high correlation between parental anxiety and child anxiety, and interventions must target parents as well as children ${ }^{14,18}$. Furthermore, parental anxiety is a relevant concern in its own right.

The STAI is a well-validated self-report measure of anxiety consisting of two versions, one assessing the dispositional or more stable trait of anxiety proneness, and the other assessing transient or situational anxiety ${ }^{15}$. Miller et al. found that parents of pediatric surgery patients experience greater levels of anxiety and higher need for information than do adults who are undergoing surgery themselves ${ }^{19}$.

During the process of MRI or CT scanning, the children are mostly prepared for the procedure with their parents accompanying them in the preparation room and they are always anxious and scary on iv line insertion unless they are sedated. And this period of crying and fear for the child inevitably makes the parents nervous, which in turn increases the child's anxiety. So the sedation of child in this period would help to overcome this problem and provide additional effect to the sedation during the radiological procedure. To establish this hypothesis, we defined the "multiphase sedation" for radiological procedures; and its application clearly revealed that sequential sedation in two phases decreased both the child and parental anxiety, and increased parental satisfaction as well. Prior to the first phase, parents' state and trait anxiety scores were similar, but after the procedure parents of the children receiving the sequential sedation were less anxious as was revealed by the lower situational anxiety scores (STAI I) of this group.

Many reports of a successful program with the use of various different forms of sedation, including oral chloral hydrate, iv pentobarbital, iv fentanyl, rectal thiopental and so forth, have been published. Sedation with parenterally administered agents proved to be advantageous and safe as it provides rapid onset and recovery of sedation, but rectally administered agents are hardly controlled with prolonged effects $6,9,13$. 
Anesthesiologists usually rely on medications that consistently provide reliable levels of deep sedation. Recently, an alternative technique describing the use of rectally administered midazolam and S-(+)-ketamine was described. This technique was superior for a standard technique of general anesthesia with endotracheal intubation ${ }^{3}$. Sedative premedication with benzodiazepines is clearly effective in reducing anxiety and the amnesic effects may also help to reduce future distress with anesthesia. Negative postoperative behavior may be reduced due to reduced preoperative anxiety or due to midazolam related amnesia. It has been shown that recall of going to sleep is lesser in midazolam-treated children compared with control ${ }^{20}$. Anterograde amnesia occurs as early as $10 \mathrm{~min}$ after administration of oral midazolam ${ }^{21}$.

Comparing our two-phased procedure with sedation techniques that rely mainly on the intravenous infusion of hypnotic drugs, such as propofol, the dosage schedule can more easily be adjusted to the individual patient since the amount of iv supplementation that was required depended on the duration of the procedure rather than individual factors. In the case of propofol, as was shown in the study by Levati et al. ${ }^{22}$, meticulous attention to the monitored variables, such as heart rate and blood pressure, was required to titrate the infusion of propofol in accordance with the variations in the depth of anesthesia. That study also revealed that smaller children required significantly higher induction and maintenance doses (10 mg. $\mathrm{kg}^{-1} \cdot \mathrm{h}^{-1}$ vs. $7 \mathrm{mg} \cdot \mathrm{kg}^{-1} \cdot \mathrm{h}^{-1}$ ) of propofol to ensure immobilization. In our study, the procedure described could reduce the required amount of hypnotics we used for the completion of imaging, which can be considered as a secondary gain of combined agents, which in turn is a matter of our objective.

The range of recovery time following sedation for MRI with intravenous continuous infusion of propofol was reported to be $15-60 \min ^{23}$. In our study, it is clearly seen that combination of oral midazolam with the hypnotics as needed by the sequential method described reduced significantly the complete recovery time following sedation. This method also reduced the challenge of both the patient and the anesthesiologist in charge as it decreased the time of staying in the preparation room and the number of attempts for iv line insertion.

Review of claims associated with monitored anesthesia care found that $75 \%$ of patients who experienced injury related to sedation received a combination of two or more drugs, e.g. a benzodiazepine and an opioid or propofol or others ${ }^{24}$. We would like to stress that incidence of complications in this study was null for several reasons. Prior to inclusion in the study, a careful examination by an experienced anesthesiologist assured that no child with a suspected problem in airway management was included. In addition, the method was used by experienced staff only. As shown in the literature, major adverse events requiring resuscitative care occurred in $1.2 \%$ of patients given a midazolam-pentobarbital-fentanyl combination ${ }^{25}$. We are actually aware of the potential of adverse events and we use this protocol in daily practice in our institution with some measures and minor interventions, such as repositioning of the child's head and neck or removal of secretions prior to the start of scanning.

\section{CONCLUSION}

Our study indicates that a sedation technique based on multiphasic procedure not only alleviate both child and parents' anxiety but also provides advantages like less challenge for the anesthesiologist for preparing the child for imaging acquisition process, less amount of hypnotics required for a sufficient sedation, and thus, less time of complete recovery and less adverse events following sedation. We propose that "multiphase sedation" technique is a safe and advantageous technique for sedation of children for radiological imaging modalities such as MRI and CT scanning. 


\section{REFERENCES}

1. Malviya S, Voepel-Lewis T, Eldevik OP, Rockwell DT, Wong JH, Tait AR - Sedation and general anaesthesia in children undergoing MRI and CT: Adverse events and outcomes. Br J Anaesth, 2000;84(6):743-748.

2. Formica D, Silvestri $S$ - Biological effects of exposure to magnetic resonance imaging: anoverview. Biomed Eng Online, 2004;22(3):11.

3. Haeseler G, Zuzan O, Kohn G, Pienbrak S, Leuwer M - Anaesthesia with midazolam and $S(+)$ ketamine in spontaneously breathing paediatric patients during magnetic resonance imaging. Paediatr Anaesth, 2000;10(5):513-519.

4. Eric E, Weissend EE, Litman RS. Paediatric anaesthesia outside the operating room. Curr Opin Anaesthesiol, 2001;14(4):437-440.

5. Voepel-Lewis T, Malviya S, Prochaska G, Tait AR - Sedation failures in childre undergoing MRI and CT: is temperament a factor? Paediatr Anaesth, 2000;10(3):319-323.

6. Gooden $\mathrm{CK}-$ Anesthesia for magnetic resonance imaging. Curr Opin Anaesthesiol, 2004;17(4):339-342.

7. Cravero JP, Blike GT - Review of pediatric sedation. Anesth Analg, 2004;99(5):1355-1364

8. D'Agostino J, Terndrup TE - Chloral hydrate versus midazolam for sedation of children for neuroimaging: a randomized clinical trial. Pediatr Emerg Care, 2000;16(1):1-4.

9. Mc CarverMay DG, Kang J, Aouthmany M, Elyon R, Mowery JL, Slovis TL, Kauffman R - Comparison of chloral hydrate and midazolam for sedation of neonates or neuroimaging studies. J Pediatr 1996; 128(4): 5736.

10. De Sanctis Briggs $V-$ Magnetic resonance imaging under sedation in newborns and infants: a study of 640 cases using sevoflurane. Paediatr Anaesth, 2005;15(1):9-15.

11. Usher AG, Kearney RA, Tsui BC - Propofol total intravenous anesthesia for MRI in children. Paediatr Anaesth, 2005;15(1):23-28.

12. Jurgens $S-$ Sevoflurane conscious sedation for MRI scanning. Anaesthesia, 2003;58(3); 296297.

13. Usher AG, Kearney RA - Anesthesia for magnetic resonance imaging in children: a survey of Canadian paediatric centres. Can J Anaest, 2003;50(4):425.

14. Kain ZN, Mayes LC, O'Connor TZ, Cicchetti DV - Preoperative anxiety in children: Predictors and outcomes. Arch Paediatr Adolesc Med, 1996;150(12):1238-1245.

15. Spielberger $C D$, Gorsuch RL, Lushene RE - Manual for the StateTrait Anxiety Inventory. Palo Alto, The State-Trait Anxiety Inventory, 1 th ed. California: Consulting Psychologists Press, 1970, pp: 25-8.

16. Watson AT, Visram A - Children's preoperative anxiety and postoperative behaviour. Pediatric Anaesthesia, 2003;13(6):188-204.

17. Kain ZN, Wang SM, Mayes LC, Caramico LA, Hofstadter MB - Distress during the induction of anaesthesia and postoperative behavioral outcomes. Anaesth Analg, 1999;88(5):1042-1047.

18. Litman RS, Berger AA, Chibber A - An evaluation of preoperative anxiety in a population of parents of infants and children undergoing ambulatory surgery. Pediatric Anaesthesia, 1996;6(6):443-447.

19. Miller KM, Wysocki T, Cassady JF, Cancel D, Izenberg N - Validation of measures of parents' preoperative anxiety and anesthesia knowledge. Anaesth Analg, 1999;88(2):251-257.

20. Feld LH, Negus JB, White PF - Oral midazolam preanaesthetic medication in paediatric outpatients. Anaesthesiology, 1990;73(5):831-834.

21. Kain ZN, Hofstadter MB, Mayes LC, Krivutza DM, Alexander G, Wang SM, Reznick JS - Midazolam- effects on amnesia and anxiety in children. Anaesthesiology, 2000; 93(3):676-684.
22. Levati A, Colombo N, Arosio EM, Savoia G, Tommasino C, Scialfa G, Boselli $L$ - Propofol anaesthesia in spontaneously breathing paediatric patients during magnetic resonance imaging. Acta Anaesthesiol Scand, 1996;40(5):561-565.

23. Frankville DD, Spear RM, Dyck JB - The dose of propofol required to prevent children from moving during magnetic resonance imaging. Anaesthesiology, 1993;79(5):953-958.

24. Bhananker SM, Posner KL, Cheney FW, Caplan RA, Lee LA, Domino $\mathrm{KB}$ - Injury and liability associated with monitored anaesthesia care: a closed claim analysis. Anaesthesiology, 2006;104(2):228-234.

25. Serafini G, Zadra N - Anaesthesia for MRI in the paediatric patient. Curr Opin Anaesthesiol, 2008;21(4):499-503. 